\title{
Analysis of Problems in Postgraduate Entrance Education and Research on its System Constructions in the New Era
}

\author{
Ming $\mathrm{He}$ \\ School of Information and Engineering in Wuhan University of Science and Technology, Wuhan, \\ Hubei, China \\ heming@wust.edu.cn
}

Keywords: Postgraduate Entrance Education, Analysis of Problems, System Constructions.

Abstract. With the environmental changes of political economy, school culture, family education, network media, there exist plural phenomena among postgraduate in the new era, including plural value and utilitarian targets, subjective consciousness and lost responsibility, independent thought and dependent psychology, open information and confused choices. Furthermore, there exist many problems of postgraduate entrance education at present, including single subject, teacher shortage, few contents, limited forms, and poor effect. Thus, it is particularly important to construct the postgraduate entrance education system.

\section{新时期研究生入学教育问题探析及体系构建 \\ 何明 \\ 武汉科技大学信息科学与工程学院, 武汉, 湖北, 中国 \\ heming@wust.edu.cn}

关键词: 研究生入学教育; 问题探析; 体系构建

中文摘要: 随着政治经济、学校文化、家庭教育、网络媒体等环境变化, 新时期研究生群体 存在着价值多元与目标功利、意识主观与责任缺失、思想独立与心理依赖、信息开放与选择 迷㟠等多元并存现象。当前高校研究生入学教育又存在着主体单一、师资贵乏、内容单薄、 形式局限、效果不佳等现状, 构建研究生入学教育新体系就显得尤为重要。

\section{1. 引言}

《国家中长期教育改革和发展规划纲要(2010-2020年)》明确提出, 提高人才培养质量, 要牢固确立人才培养在高校工作中的中心地位, 着力培养信念执著、品德优良、知识丰富、 本领过硬的高素质专门人才和拔尖创新人才 ${ }^{[1]}$ 。高校作为高层次人才教育和培养主阵地, 要 高度重视研究生教育起始环节, 加强入学“第一堂课”的引领作用, 拓展研究生思想政治教育 新途径, 帮助研究生适应学习生活, 为国家培养出符合社会需要的研究型创新型复合人才。

\section{2. 研究生入学教育之时代背景}

改革开放以来, 国民经济飞速发展, 网络媒体蓬勃发展, 社会、学校以及家庭环境也不 断变化, 研究生群体正面临着前所未有的机遇和挑战, 主要表现在:

\section{1 政治经济环境变化, 价值多元化与目标功利性并存}

国际政治环境不断变化, 经济全球化进程也不断加快, 成长在这一政治经济环境下的研 究生群体, 其价值观念和文化思维深受影响。他们既有中华民族传统文化的熏陶, 又有西方 国家外来文化的感染，价值观念相互交融，文化思维日益开放，多元化价值观正逐步形成。 
他们有着对社会现象的自我认识, 有着对人生价值的自我追求。然而利益关系调整、收入差 距扩大、阶层流动趋缓等社会变革, 深深影响着转型社会中的研究生群体, 他们不仅思想成 熟, 伴随价值取向多元化, 还带有实用主义倾向和功利主义色彩。

\section{2 学校文化环境变化, 意识主观化与责任缺失性并存}

高校开放包容的育人理念, 自由青春的校园文化, 正深刻培育和熏陶着研究生群体。成 长在这一学校文化环境下的研究生们, 具有独立思考、自由实践的精神面貌。他们一边追求 真理、崇尚自然, 一边表达心声、注重内心体验。内心世界正日益丰富，主观意识也日益浓 厚。在具体学习过程中, 他们常常以个体为中心来认识世界, 由于过于注重自我内心感受, 他们往往忽视他人存在, 在重视个人利益争取的同时, 又忽视社会责任的履行。群体正呈现 出彰显个性与忽视他人并存、展示自我与忽视集体并存的二元现象。

\section{3 家庭教育环境变化, 思想独立化与心理依赖性并存}

随着经济收入提高, 众多家庭重视子女教育, 家庭环境对研究生群体的思想发展和心理 形成产生了重要影响, 具体表现为: 认知视野更加宽广, 心理成熟度相却对滞后。他们思想 独立, 敢于标新立异; 他们言行自由, 乐于追求自我。由于成长环境单纯、社会阅历过浅等 现实因素, 在面对多元社会的各种变化时他们缺乏足够的心理准备, 造就了群体的心理依赖 性。他们敢于尝试新鲜事物却又害怕挫折, 他们言行独立却又缺乏安全感, 最终表现为思想 独立的同时又缺乏抗挫败能力。

\section{4 网络媒体环境变化, 信息开放化与选择迷恫性并存}

互联网媒体时代, 网络技术迅速发展, 信息量呈现出几何级爆炸式增长。成长在网络媒 体时代的研究生, 他们善于利用网络资源获取信息, 喜好通过搜索引擎来解答疑惑, 他们热 衷即时通讯进行信息交流, 喜欢通过微博来表达情感。他们接受丰富多元的价值观念和思想 元素, 认知视野开阔、知识结构丰富。作为接受新知最快的群体, 他们不可避免地会受到网 络不良文化的影响, 加之自控力不足、鉴别能力差等因素, 他们很容易在网络世界中迷失自 己，忘记人生理想和奋斗目标。

\section{3. 研究生入学教育之问题探析}

我国高校自开展研究生教育以来, 在研究生入学教育上不断进行理论探索和教学实践, 形成了比较完整的入学教育体系。但在具体实施过程中还存在着各种问题, 主要表现在:

\section{1 入学教育主体单一, 缺乏系统性}

入学教育是一项全面系统的工程, 要依靠学校统筹教学资源、协调相关部门共同参与才 能推进。实际情况却是由学生工作队伍承担, 院系之间缺乏交流, 职能部门缺乏参与, 使入 学教育陷于边缘化境地, 远不能满足新生适应社会发展的需要。国外入学教育则更具系统性, 比如耶鲁大学设立新生事务办公室专职负责新生工作, 职能部门、院系以及学生组织共同参 与, 发挥作用全力为新生服务 ${ }^{[2]}$ 。由多个教育主体负责开展, 教育内容更加系统全面。

\section{2 入学教育师资荝乏, 缺乏科学性}

研究生是我国高校培养的高层次研究型人才, 作为特殊的被教育群体, 有着独特求知需 要, 需要专业化师资队伍给予指导。然而在大多数高校, 入学教育工作往往由学生工作队伍 承担, 队伍参差不齐, 理论水平有限, 教育缺乏深度。国外大学却有专业队伍开展主题教育, 比如英国高校非常重视学生对网书馆资源的利用, 他们会安排专门的图书管理员介绍馆藏资 源以及使用方法 ${ }^{[2]}$ 。整合专业资源开展主题教育, 教育力量更加充足, 教育方法也更加科学。 


\section{3 入学教育内容单薄, 缺乏层次性}

在大多数高校, 研究生入学教育还是局限于校规校纪讲解、院系专业介绍等常规内容, 缺乏人际沟通、社会需要等人文素养培育, 更缺乏专业学习、职业规划等专业素养指导。教 育内容简单陈旧，教学方式缺乏交流互动。国外大学入学教育则更具层次性，比如美国旧金 山州立大学为新生提供医疗保健、社区治理、法律咨询等个性化服务内容; 澳大利亚的大学 则为新生开展校园生活安全、图书馆资源利用等各种入学辅导课 ${ }^{[2]}$ 。教育内容从医疗法务到 安全治理, 从专业学习到知识运用, 教育内容丰富全面。

\section{4 入学教育形式局限, 缺乏多样性}

当前研究生入学教育方式主要还是以集中讲授为主, 多采取开学典礼、主题班会、学术 讲座等单向传输教育方式, 实践体验活动非常少, 教学缺乏有效感染力和创新性, 无法调动 学生兴趣, 更无法引起学生共鸣。国外大学则形式多样, 如美国耶鲁大学为新生精心设计适 应性训练体系, 编写手册开设网站, 开展人际关系管理和学术指导, 方式通常包括志愿者活 动、午餐会、新生研讨会、咨询辅导和专题讲座等教育活动 ${ }^{[2]}$, 教育形式丰富多样。

\section{5 入学教育效果不佳, 缺乏整体性}

当前大多高校按部就班的开展入学教育, 在内容、形式和时间上缺乏整体规划和协调, 教育效果并不是很理想。国外大学则邀请专业人士开展专业教育, 例如生活安全系列课程涉 及到消防、交通、医疗、法律、保险等内容, 学校会邀请消防部门、交通警察、社区医院、 法律援助中心、保险公司等专业人士来校为新生讲课 ${ }^{[2]}$, 集中进行知识讲解和技能培训。理 论知识传授和现场实践学习相结合，教育效果更加突出。

\section{4. 研究生入学教育之体系构建}

为适应不断变化的内外部环境, 破除高校入学教育过程中存在的问题, 开创新时代背景 下研究生创新人才培养的新局面, 本文构建了“五位一体”的研究生入学教育新体系。

\section{1 建立多元性主体参与体系}

入学教育涉及到从专业成才到精神成人等各方面指导，应由职能部门和院系共同承担， 建立以院系为主、职能部门为辅的多元性主体参与体系。院系方面开展常规教育, 比如校规 校纪、入学适应、人文励志等教育, 由学院领导、专业教师、辅导员等多元主体选择各自擅 长的领域开展。职能部门开展专题教育, 比如研究生院开展学术道德与诚信教育, 学工处开 展职业生涯规划教育，保卫处开展校园安全与保卫教育等。多元性主体共同参与和开展，使 教育内容更权威、知识体系更专业。

\section{2 建立专业性师资队伍体系}

面向研究生群体的入学教育, 对教育主体提出了更高要求, 仅仅依靠工作在学生一线的 班主任、辅导员是远远不够的。具体表现在: 教育者不仅要具有专业化理论知识体系, 还要 具有一定教学水平和实际操作经验。比如心理健康教育, 要求授课教师具有心理健康的理论 知识, 还要有多年实际心理辅导经验。首先, 高校应该有针对性引进专业人才, 利用专业教 师学科背景, 教育新生掌握解决问题的新理论, 为学生提供符合社会新形势的入学教育。其 次, 高校应加强入学教育主体的学习和培训工作, 提高教育者理论体系的同时, 加强教育者 授课水平和实践能力, 切实为入学教育提供高水平的人才队伍保障。

\section{3 建立全面性教育内容体系}

新生入学教育大多在开学第一周集中开展, 内容仅仅局限于校规校纪、入学适应等常规 教育, 并没有全面考虑社会形势对研究生群体提出的新要求。高校应当将教学管理和新生特 
点结合起来, 顺应人才成长规律、把握时代变化趋势, 对研究生入学教育进行统筹规划, 建 立全面系统的教育内容体系。既要有人生价值培育, 比如理想信念教育、责任意识教育, 也 要有专业成才熏陶, 比如科研诚信教育、培养过程教育, 还要有职业规划指导, 比如职业生 涯教育、创新创业教育。将人生价值、专业成才、职业规划紧密结合, 全面系统地学习教育 内容，使入学教育真正成为学生的人生导航者、学业帮扶者、职业引路者。

\section{4 建立多样性教育方式体系}

其一，理论学习与生活实践相结合。理论学习主要以教师授课为主的传统灌输模式，通 过熏陶感染来提高新生人文素养和科学精神。生活实践主要以情景模拟为主的新生体验模式, 通过实际操作加强学生自我教育和学习。其二, 教育引导与榜样激励相结合。仅仅通过理论 和方法的传授是不够的, 还要借助榜样力量的激励作用。通过道德模范、党员先进、创业典 型等, 培养争先创优的学习氛围, 树立榜样的示范力量, 加强研究生自我激励和成长。其三, 集体教育与分散教育相结合。入学教育通常集体性开展, 新生共同学习教育内容。实质上, 研究生具有不同的学科方向和专业领域, 将专业成才教育按照不同研究方向分散开展, 精细 化地有针对性地实施教育, 教育方式更具有科学性。

\section{5 建立有效性考核评价体系}

考核评价是入学教育过程中不可缺少的重要环节，通过有效考核评价体系，改进教育方 法、优化教育过程、提高教育效果, 使研究生能够在入学教育过程中有所收获。其一, 采取 封闭式定量评价方式。科学引进入学教育考核评价量化指标，让新生对每一次教育内容、方 式、效果进行打分，根据打分结果对入学教育进行评估和修正。其二，采取开放式定性评价 方式。要求新生提交学习心得, 鼓励新生提供改善建议, 通过心得和建议对入学教育进行反 馈和完善。通过多次定量和定性评价, 不断改善和优化教育体系, 提高教育内容科学化水平, 改进教育方式规范化层次, 调动教育工作者主动性和积极性。

\section{5. 结束语}

研究生入学教育作为研究生整体教育过程中的“第一堂课”, 是研究生创新教育与人才培 养的重要组成部分, 是加强研究生思想政治教育的有力抓手。为适应研究生入学教育新时代 要求, 破除研究生入学教育过程中存在问题, 本文构建了“五位一体”的研究生入学教育体系, 为深化研究生教育改革、促进研究生教育长远发展提供理论支持和实践参考。

\section{References}

[1] Ministry of Education, The national outline for medium-and long-term educational reform and development(2010-2020), 2010.

[2] Y Liu, The foreign college freshmen education and its reference and inspiration, Journal of Jiaozuo Teachers College, Vol.29, pp. 72-74, 2013. 